\title{
Lessons Learned in the Creative and Entertainment Industry for User Engagement Applied to Museum Collections 3D Digitization Strategy.
}

\author{
Jiri Frank ${ }^{\ddagger}$, Lukas Mensik $§$ \\ ‡ National Museum, Prague, Czech Republic \\ $\S$ Barbucha studio, Prague, Czech Republic
}

Corresponding author: Jiri Frank (iiri frank@nm.cz), Lukas Mensik (lukinec@barbucha.studio)

Received: 11 Apr 2018| Published: 04 Jul 2018

Citation: Frank J, Mensik L (2018) Lessons Learned in the Creative and Entertainment Industry for User Engagement Applied to Museum Collections 3D Digitization Strategy. Biodiversity Information Science and Standards 2: e25712. https://doi.org/10.3897/biss.2.25712

\section{Abstract}

Museums are places embedded in history, knowledge, exploration, science, art, inspiration and adventure, expressed through their collections, galleries and the passion of their employees/staff. However, are museums good at transforming what they have into something valuable and relevant for the audiences of today? Something that will give them additional value after their visit? What is the meaning of museums in the age of the Internet, Wikipedia and virtual reality? Why would you spend time visiting and revisiting a museum when you have so many opportunities for distraction elsewhere?

Indeed what is unique to museums are the real physical collections which you cannot see anywhere else and the data which those collections represent. But what if you can give the users the opportunity to interact with the collections in a way they have never tried before. Perhaps the future lies in digital 3D interaction. You can give people additional value beyond the walls of your institution in ways that stay with them long after they have left the Museum. By connecting technology, resources and experience, museums can adapt solutions that are already explored and proven by other industries. Then the disruption can begin. Your museum can be a place where the future is born. 
There are several opportunities which are now more open than ever:

- Embrace innovations of Apple, Google, Microsoft, Facebook in the fields of AR / Augmented Reality, 3D, and VR / Virtual Reality.

- Master the 3D scan process, tools and best practices.

- Understand 3D reconstruction, optimization and creation of realistic, physically based, real-time materials.

- Use technology, workflows and tools at the same proficiency and quality as creative and entertainment industries.

- $\quad$ Learn about digitized data usage for inspiration, creative works and new exciting forms of education.

- Transform the experience and deep expertise of museum professionals in ways that can actively influence everyday life of people across continents.

- Digitized collections and shared resources as a bridge between professions to become a foundation for creative and education communities and to open new collaborations.

- Be open to empower individuals, communities, and companies to evolve the content you provide in creative ways.

The content and expertise held in museums can be a foundation for new things and inspiration for creators and thinkers of tomorrow. The museum need not beg for attention, it would be a place that people actively seek. In this presentation we would like to explain why 3D digitization matters and how it can significantly help museums fulfill and extend their mission when it's done right. Let us demonstrate what "right" means in this context, how we are doing it, and how important it can be for museums and their audience.

\section{Keywords}

3D digitisation, creative industry, augmented reality, virtual reality, 3D scan, PhysicallyBased Materials (PBR), Blender, Open Source, 3D Builder, Unreal, Unity, digital repatriation.

\section{Presenting author}

Jiri Frank 